\title{
SOCIAL RELATIONSHIPS OF MEN AT RISK FOR AIDS
}

\author{
Kerth O'Brien, ${ }^{1}$ Camille B. Wortman, ${ }^{2}$ Ronald C. Kessler ${ }^{3}$ and Jill G. Joseph ${ }^{4}$ \\ ${ }^{1}$ Department of Psychology, Portland State University, P. O. Box 751, Portland, OR 97207, U.S.A. \\ ${ }^{2}$ Department of Psychology, State University of New York, Stony Brook, NY 11794, U.S.A., ${ }^{3}$ Institute \\ for Social Research and ${ }^{4}$ Department of Epidemiology, The University of Michigan, Ann Arbor, MI \\ 48109, U.S.A.
}

\begin{abstract}
Survey data collected in 1984-85 from a community sample of 637 gay and bisexual men were used to determine the features of social relationships that were most conducive to changes in both psychological health and AIDS-related sexual risk behavior. Multiple regression analyses showed that both the perceived availability of social support and the absence of conflicts in the social network were related to improve psychological health. At the same time, the subjective experience of integration into social networks was associated with increased psychological distress, and validation (the experience of being accepted by others) was related to a higher level of risk activity. These findings are discussed in terms of the social relationships among community members that share a common stressor-in this case the shared problem of being at risk for AIDS.
\end{abstract}

Key words - social relationships, AIDS, HIV

\section{INTRODUCTION}

"The best defense we have against AIDS is each other." So reads the caption on a poster designed to stop the spread of acquired immune deficiency syndrome. The poster reminds its readers that one way to prevent the transmission of the AIDS virus is to support other people in their efforts to follow the recommendations for AIDS-preventive behavior. In this sense, the problem of AIDS prevention resembles the problems of smoking cessation, weight loss, or the prevention of teenage pregnancy. Yet AIDS prevention programs differ from most other prevention efforts in that AIDS itself is a near-fatal syndrome, people with AIDS experience an unusual degree of stigmatization, and the risk of AIDS affects not only isolated individuals but connected members of social groups [1]. In the United States, $65 \%$ of adults or adolescents with AIDS are men who have been sexually active with other men [2]; therefore AIDS in the United States is especially problematic for members of the gay male community.

The prevention of AIDS holds implications not only for behavior but also for psychological health. For gay men at risk, AIDS prevention means the development of new sexual habits. This is a difficult issue because sexual expression is seen by many gay men as a fundamental part of being gay. Consistent with this view, research conducted prior to the AIDS epidemic has found that activities of sexual expression were reinforced to gay men's psychological health. In addition, social relationships have been found to influence the extent to which gay men had positive feelings about their own gay identities [3-6]. For these reasons, social relationships are likely to affect the psychological adjustments that accompany changes involved in AIDS-preventive behavior.

Although related to each other, psychological health and AIDS-preventive behavior may be affected by the social environment in different ways; yet few studies have examined both of these outcomes at once [7]. The present study employed a longitudinal design to examine the effects of social relationships on the psychological health and health behaviors of gay men at risk for AIDS.

House, Umberson and Landis [8] recently presented evidence that health is affected by both the structures and processes of social relationships. The current study examined relationship structure through measures of two aspects of social integration-objective integration (specifically, involvement in voluntary organizations) and subjective integration (such as whether a person feels like part of a group of friends). Relationship processes were studied through the inclusion of two key components of the individuals perception of being supported by others [9]-perceived support (the belief that other people would provide one with support for whatever situations might arise) and the sense of validation (the belief that other people accept one for oneself). In addition, because of growing evidence about the importance of negative features of social relationships, the study examined the effects of social conflict that participants experienced [10].

A recognition of the multifaceted nature of social relationships may be especially appropriate in terms of the experiences of gay men. Gay men often confront rejection from family members or former friends due to their risk status [11]. In addition, persons who are well-integrated into gay male social networks are likely to have experienced the death of 
someone close to them [12]. Furthermore, while some of the social circles in a given community of gay men may support behavior change, other circles may not [13]. Thus, gay men confront stresses due to both their own risk for AIDS and the situations related to AIDS for other people they know.

Recent research has suggested that individual differences may influence the effect of social relationships on health related outcomes [14]. In our study, we recognized that persons with high self-esteem and mastery may be more likely to look for support than persons without these resources. These people may also be more attractive as friends, which would make them more successful in their support-seeking efforts [15]. Furthermore, the very presence of their own psychological resources might render some of their social relationships less influential. For example, persons with high self-esteem may be less vulnerable to outside criticisms that others [16]. With this in mind, we included the constructs of self-esteem and mastery as controls when we examined the effects of social relationships.

In addition to self-esteem and mastery, broader differences of social position may directly or indirectly influence psychological health or health behaviors. For example, it is well established that higher socioeconomic status is associated with better physical and psychological health [17], and several epidemiologic studies have found that married persons enjoy better health and well-being than others [18, 19]. In our study, we therefore included several background characteristics as statistical controls, such as age, race, educational status, income, and involvement in a monogamous relationship (using the latter as an analogue to marital status among this population of gay men).

In summary, we examined the effects of integration, support, and conflict on both AIDS-preventive health behaviors and on distress or lack of well-being. We also asked whether the effects of social relationships were indeed due to the relationships themselves and not instead to dispositional or background characteristics of the individual at risk. Finally, we examined the possibility that individual differences in self-esteem or mastery might explain the effects of social relationships on psychological health and risk behavior.

\section{METHOD}

\section{Participants}

The data reported in this paper were collected from 637 gay and bisexual men as part of the Coping and Change Study (CCS); the CCS served as a psychosocial supplement to the Chicago site of the Multicenter AIDS Cohort Study (MACS), a biomedical study of the natural history of AIDS [20]. All MACS participants had been homosexually active within the four years prior to study enrollment and were therefore considered to be at risk for AIDS. None of these men reported that they had been paid for engaging in sexual activity.

It is impossible to identify the population of homosexually active men [21], therefore we cannot know to what extent our sample is representative of gay men in the Chicago area. The Coping and Change Study sample is unlike the general Chicago population in that the sample is rather homogeneous with regard to race $(92.6 \%$ white) and education $(68.6 \%$ collegeeducated) characteristics. Respondents varied widely, however, in age, ranging from 19 to 73 years with an average of 35.7 years. The prototypic respondent was employed $(89.9 \%)$ with an annual income of $\$ 24,500$. Respondents had been homosexually active for an average of 16.1 years. The sample resembled cohorts recruited in other cities for similar biomedical assessments [20].

Each respondent completed a self-administered questionnaire between June, 1984, and February, 1985 , and a second questionnaire approximately 6 months later. This timespan was adopted so that the MACS could collect biomedical data. Seventy-five percent $(74.9 \%)$ of MACS participants who were approached at the first timepoint agreed to participate in the CCS, and of these, $81.7 \%$ participated again at Time 2 . During this period, no respondent in the study developed AIDS. In addition, this timespan took place before HIV antibody tests were available; therefore no men in this study had yet been tested for HIV antibodies.

\section{Measures}

Assessment of social relationships. Five scales were used to examine features of social relationships. Two dimensions of social support that previous studies have shown to be key components of relationships processes [9] were measured here-perceived availability of support (seven items, Cronbach alpha $=$ 0.873 ) and validation (three items, alpha $=0.775$ ). The negative aspects of relational processes were measured as social conflict, pertaining to conflictual and disappointing experiences (seven items, alpha $=$ 0.820 ). The structural features of social ties were measured as objective social integration, pertaining to the respondent's involvement in voluntary organizations (two items, alpha $=0.886$ ) and as subjective social integration, addressing the respondent's own view of his network involvement (seven items, alpha $=0.820$ ).

Assessment of personal resources and background characteristics. Self-esteem (Cronbach alpha $=0.856$ ) was measured through use of 10 items drawn from Rosenberg [22], and mastery (alpha $=0.772$ ) through use of seven items drawn from Pearlin, Lieberman, Menaghan and Mullan [23]. We also included measures of age, income, educational level, primary relationship status, ethnicity (white/nonwhite), whether the respondent thought of himself as exclusively homosexual, and the number of years since the respondent's first sexual experience with another man. 
Assessment of outcomes: sexual risk behaviors. Questionnaire methodologies have been found to be efficient and reliable for one-month retrospective reports of sexual risk behavior $[24,25]$. The CCS used self administered questionnaires that respondents completed about 2 weeks after their visit to the biomedical study site. Respondents were asked about their sexual behaviors during the previous month. Three behaviors that were assessed were widely understood, at the time of the data collections, to be associated with risk for AIDS [26]: (1) the respondents total number of sexual partners; (2) his number of anonymous sexual partners; (3) his number of risk exposures, that is, the sum of times that he engaged in any of three activities known at the time of data collection to carry risk of HIV infection: receptive anal-genital sex, receptive oral-genital sex, and insertive oral-anal sex. The first and second of these measures are related in that anonymous partners are necessarily included in the total number of sexual partners.

Assessment of outcomes: Psychological health. Measures of psychological symptomatology including a subset of $11 \mathrm{itcms}$ pertaining to depression and 6 items pertaining to anxiety from the Hopkins Symptom Check List (SCL-90) [27]. At the study's baseline, Cronbach alpha coefficients for these scales were 0.91 for depression and 0.81 for anxiety. Eleven measures of well-being were adapted from items by Veroff, Douvan and Kulka [28] and Andrews and Withey [29], including questions about satisfaction with major life roles, global life satisfaction, and happiness (alpha $=0.82$ ). In order that coefficients for well-being could be readily compared with those for depression and anxiety, we reversed the direction of our well-being scores such that a higher score indicated lower well-being.

\section{RESULTS}

Descriptive information on social relationships, psychological health, and risk behavior

Behavioral measures indicated that between the two timepoints of study, the mean number of sexual partners per month declined from 3 to 2 partners per respondent. The median number of risk exposures declined from 10 to 7 . These trends have been replicated in similar cohorts $[30,31]$.

\footnotetext{
*The coefficients presented in this table were obtained after outliers were deleted. Data were inspected for outliers by reviewing the values of Cook's distance $(D)$ [35] obtained for regression equations for Model 6. Two cases were found for the equation predicting number of exposures, one of which was also found for the equation predicting number of anonymous partners, for which $D$ exceeded 0.50 . No other values of $D$ approached these values. These cases were deleted from analyses. The final coefficients are presented in Table 1.
}

Anxiety and depression subscales correlated 0.77 in this study, a level similar to other reports. Anxiety and depression have been shown to represent empirically distinct aspects of psychological symptomatology $[32,33]$. In this study symptoms of distress have been distinguished conceptually from low levels of psychological well-being [34], which correlated 0.75 with depression and 0.54 with anxiety.

\section{Effects of mastery and self-esteem}

Before examining the effects of social relationships, we estimated a series of bivariate regression analyses in which self-esteem and mastery predicted support, conflict, and integration at Time 1. Self-esteem significantly predicted all five social resources, and mastery predicted four of the five. Based on these results, self-esteem and mastery were included as controls in subsequent regression models.

\section{Effects of support, conflict, and integration}

Subsequent regression models included perceived availability of support, validation, conflict, and both objective and subjective integration as central predictors of interest. The dependent variables included the three measures of psychological health and three measures of sexual risk behavior.

Multivariate regression models included controls for self-esteem and mastery as well as several background characteristics: age, income, education, race, the number of years the respondent had been homosexually active, and whether the respondent viewed himself as exclusively gay. For regressions involving the psychological health outcomes, an additional control was included for whether the respondent was involved in a monogamous relationship, as an analogy to heterosexual marital status. For risk behaviors, however, being monogamous might be seen as an outcome in itself; therefore the monogamy control was omitted from behavioral analyses. Finally, all longitudinal analyses controlled for Time 1 levels of the outcome variable, in order to examine the effects of social ties on changes in psychological health and risk behavior.

Table 1 presents the results of longitudinal regression equations for the effects of support, conflict, and integration. ${ }^{*}$ Column a represents five separate regression equations in which only one feature of social relationships was used to predict changes in mental health or risk behavior (Models 1-5). Perhaps the most interesting finding here involved the effect of validation on risk exposures. Even the men receiving the most validation from their social ties reduced their number of exposures; but they did so less than other men. In addition, men who reported higher levels of conflict and objective integration also reported increased symptoms of depression.

Column $b$ shows the results of analyses that used all five features of social relationships together as predictors, in addition to the control variables (Model 6). As reflected by the coefficients $R^{2}$, social 


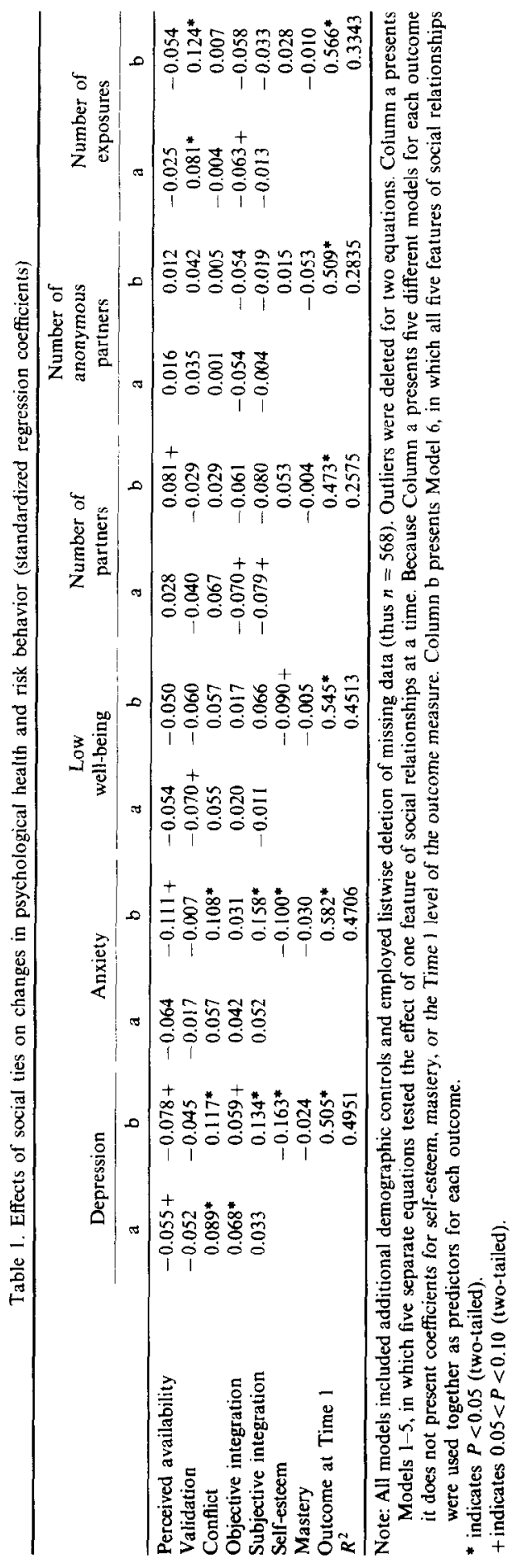

relationships were more predictive of changes in psychological health than of changes in risk activity. Men who experienced more conflicts and disappointments in their relationships at Time 1 showed increased depression and anxiety at Time 2; still, conflict had no significant relationship to risk behavior. Men who reported a higher degree of subjective social integration- those, for example, who felt themselves to be part of a group of friends and not to need any more friends than they had -also showed increased symptoms of depression and anxiety.

Column ' $b$ ' also indicates that men who perceived more support to be available to them at Time 1 showed lowered anxiety and depression at Time 2. Men who reported more validation at Time 1 -for example, those who felt that people close to them tended to size up situations and people the same way that they did-again reported a smaller decrease in exposures to risk activity than did other men.

Validation was examined more closely among subsamples of men at especially high risk in order to understand whether its effects on these men might be especially pronounced. The five-feature model was rcplicated among threc subsets of respondents at Time 2: those who had been exposed to risk activity, those who had more than one partner, and those who had any anonymous partners. Among the men with multiple partners, validation was negatively related to the number of partners $(\beta=-0.13, P<0.05)$. Validation thus had two effects: among the sample as a whole, it was related to a smaller decrease in exposures, but among the men with multiple partners, it was related to a decrease in their number of partners over time. It may be that men who feel validated by their relationships, especially by their sexual relationships, are inclined to pursue sexual activities with their current partners and are not inclined to see more partners.

Table 1 shows that the effects of social relationships appear stronger for depression and anxiely for the model using all five features of relationships together (column b) than for models using each feature separately (column a). These findings suggest the dynamic nature of support, conflict, and integration. For example, visual inspection of the simple relationship of subjective integration to changes in depression is close to zero ( 0.033 in column a). This masks, however the significant effects of subjective integration that are both direct $(0.134$ in column $b$, $P<0.05$ ) and indirect-for example, through its 0.54 correlation with perceived availability of support, which in turn has a significant negative effect $(-0.078$ in column $b,[P<0.05)$ on depressive symptoms. In sum, the stronger set of coefficients in column b suggests that in order to understand social relationships accurately, one must examine their various dimensions together.

All models represented in Table 1 included controls for self-esteem, mastery, and demographic characteristics. Because column a summarizes findings from 
five separate models for each outcome, column a reports only the coefficients for social relationship features. Self-esteem and mastery coefficients are reported in column $b$.

As an additional precaution in the analyses of these data, the possibility was considered that some men may have experienced unusually high levels of activity at the first study timepoint, and thus, their apparent reduction in activity between Times 1 and 2 may have represented a correction in fluctuation rather than a meaningful change in behavior. At the first timepoint respondents were asked, "How would the number of your sexual partners during the past month compare with your usual number during a typical month in the past half year?' Respondents who indicated they generally would have had many fewer partners were omitted from analyses that replicated the models in Table 1 . Of the nine significant coefficients in Table 1 , eight retained significance in the replication. Thus, the findings reported in Table 1 were essentially robust against these temporary fluctuations in risk activity.

Interactive effects of social relationships, self-esteem, and mastery

We also asked whether the effects of social relationships depended upon the individuals level of personal self-esteem or mastery. The multiple regression models were replicated with the addition of interaction terms between mastery and each measure of social ties.* None of these interaction terms was significant. These terms were then replaced with interactions for social ties and self-esteem. One interaction was significant when the $P$ level was adjusted for the number of significance tests involved: high self-esteem reduced the impact of low validation on depression $(\beta=0.79, P<0.01)$.

\section{DISCUSSION}

In this study, we found that the perceived availability of support led to reduced symptoms of depression and anxiety, but that the experience of social conflict led to increased symptoms in these areas. The subjective experience of being integrated into social networks led to higher levels of distress. In addition, men who were validated by their social relationships showed less of a decrease in their exposures to risk activity than other men during the course of the study. Our findings on availability and conflict can be considered replications of the previous support literature, but our findings for validation and social

\footnotetext{
*Adjustments were made to alpha in evaluating these coefficients, using the formula $\alpha=(0.05) \times$ (number of significant coefficients at $P<0.05$ )/(number of equations tested). Thus, for psychological health outcomes, the critical alpha value used for each coefficient was (4) $(0.05) / 30=0.0066$; for risk behaviors, the critical value was $(2)(0.05) / 30=0.0033$.
}

integration differ in their direction from prior reports. The gradual construction of social norms for safer sexual activity and the community nature of shared social stressors produced by this epidemic may have led to our results, as we suggest below.

\section{Personal resources and social relationships}

Validation from others in the social network had a more powerful effect on reducing symptoms of depression among those men with low self-esteem than among others. This finding suggests that, for some individuals at least, what is lacking in self-esteem can be replaced with approval from others in the personal network. For example, Hazan and Shaver [36] have noted that people with an anxious/ambivalent attachment style are lonely, have more sclf-doubts than most people, and worry about whether their romantic partners will leave them. Such an attachment style may either erode self-esteem or reflect an already low self-esteem; it may lead individuals to be more emotionally dependent on others in their personal network, thus explaining the interaction we observed. Although we did not measure the attachment construct here, future studies would do well to examine the causal links among self-esteem, validation, and attachment style.

\section{Evidence for the effects of social relationships}

We examined three features of social ties-support, conflict, and integration--that are rarely studied together. We found, as expected, that both the perceived availability of support and the absence of social conflict were associated with lowered distress.

We also found, however, that men who were validated by their social relationships showed less decrease in their risk behavior than other men. Research on other health threats would have predicted the opposite [37]. Yet AIDS differs from most other health threats in part because so many of the people at risk share membership in the same community. At the time of our data collection, the men who had most effectively reduced their own risk activity were also pioneering the formation of new community norms in favor of 'safer sex' [38]. In this regard they were innovators of a new health practice in a sense similar to that described by Becker [39]. As revealed in post hoc analyses, these men were significantly more likely to be involved in gay-related groups or organizations, suggesting they may have seen themselves as opinion leaders in the community. While the new norms were developing these men did not feel that others approved of how they felt about safer sex, or sized things up the way they did. Yet, perhaps in part because of their leadership, time has brought many more gay men subsequently to adopt the 'safer sex' guidelines [31]. As the epidemic continues, further research with men at risk for AIDS might determine whether the men who follow safer sex guidelines come to feel more validated by people close to them. 
We also found that the subjective experience of being connected to other people was associated with higher levels of distress. While past research has implicitly regarded social integration as a form of support, or at least congruent with support [8], we found that support and integration had opposite effects. When we included all five features of social rclationships together as predictors, the significant coefficients were larger in size than they had been in the models that considered these features separately. Given the modest correlations among our predictors, this result is unusual. Why did this occur?

We believe this occurred because, in a situation such as the AIDS epidemic, being connected to other pcople brings both costs and benefits. Unlike persons affected by most health-related stressors, gay men at risk for AIDS are likely to be integrated into networks of others who share their risk status. Social integration puts gay men into heightened contact with others experiencing this epidemic and makes them more aware of the AIDS-related events occurring to people they know. In particular, many gay men have the experience of knowing several people who have been diagnosed or who have died of AIDS $[40,41]$. Social integration in this situation makes supportive processes, such as validation and perceived availability, possible, but it also brings experiences that are troubling.

This interpretation is corroborated by work on disaster experiences that are shared by an entire community. Pennebaker and Harber [42] have reported that persons who lived in the San Francisco Bay Area during the 1989 earthquake were affected by that disaster not only directly but also through disturbing interactions they had with their social network members. Similarly, Hobfoll and London [43] have demonstrated that in wartime situations, women civilians who interacted frequently with friends and neighbors also experienced more distress than others. For these people, as for our respondents, social integration was double-edged.

Further studies of men at risk for AIDS might focus more closely upon the AIDS-related events that occur in social networks of men at risk. As the epidemic widens and the tasks of caring for people who are sick (for example) become more burdensome, one might expect that subjective integration will have an even stronger negative impact. Alternatively, as caregivers also become more numerous, integration could start to bring more benefits. In addition, support groups for individuals at risk may provide structured, facilitated environments for the expression of feelings, observation of successful problem-solving skills, and receipt of emotional support. In this way support groups go beyond the unfacilitated interactions of daily life among community members to assist individuals who confront problems associated with the epidemic [44].
Comparison of effects on psychological health and health behavior

The current study is one of the few that we know to have examined both mental health and behavioral outcomes. We found that social ties had a much weaker influence on the reduction of AIDS-related risk behavior than on changes in psychological health. A limitation of our study is that these findings may have reflected differences in specificity, in that our measures of AIDS-related risk behaviors were specifically linked to this epidemic, while our measures of psychological health were not. Future research might employ both global and stress-specific measures of support in order to examine the possibility that global support may influence psychological health and well-being, while tailored support may influence particular health behaviors.

Similarly, features of social relationships appear to have had a weaker influence on positive psychological health than on the symptoms of depression and anxiety. This may reflect the specificity of the symptom measures in comparison to the well-being construct, which included components of happiness, life satisfaction, and various role satisfactions. Alternatively it may reflect an asymmetry in the influence of the social environment on positive and negative features of psychological health [45].

Our results underline the importance of the multidimensional study of social ties. Among gay men at risk for AIDS, social relationships are less influential for behavior change than they are for changes in psychological health. Both the perceived availability of social support and the lack of conflict in the person network are predictive of lowered distress. Our findings emphasize, however, that when a stressor is shared by an entire community-as in this situation, in which gay men in general share the problems of the AIDS epidemic-the subjective experience of being close to other people brings burdens as well as benefits. These findings support the development of interventions to expand the training of AIDS caregivers beyond the population of individuals at risk.

Acknowledgements--The authors thank David Morgan, Peter Goldblum, Berit Ingersoll-Dayton, David Ostrow, Susan Wladaver-Morgan, and anonymous reviewers for helpful comments on this work. We are thankful to participants in the Coping and Change Study and to Michael Eller of the Howard Brown Memorial Clinic in Chicago for his unfailing help in data collection.

This work was sponsored by funding from the National Institute of Mental Health (2R01 MH39346-02A1, $1 \mathrm{R} 03 \mathrm{MH} 45640-01 \mathrm{Al}$ ) and from The University of Michigan.

\section{REFERENCES}

1. Herek G. M. and Glunt E. K. An epidemic of stigma: Public reactions to AIDS. Am. Psychol. 43, 886-891, 1988.

2. Centers for Disease Control. HIV/AIDS Surveillance Report (Table 10). U.S. Centers for Disease Control, Atlanta, GA, 1992. 
3. Acevedo J. R. Impact of risk reduction on mental health. In What to do About AIDS (Edited by McKusick L.), pp. 95-102. University of California Press, Berkeley, CA, 1986.

4. Dannecker M. Theories of Homosexuality. Gay Men's Press, London, 1981

5. Kegeles S. M., Adler N. E. and Irwin C. E. Jr Sexually active adolescents and condoms: Changes over one year in knowledge, attitudes, and use. Am. J. publ. Hlth 78, $460-461,1988$.

6. Weinberg M. S. and Williams C. J. Male Homosexuals: Their Problems and Adaptations. Oxford University Press, New York, 1974.

7. Okun M. A., Stock W. A., Haring M. J. and Witter R. A. Health and subjective well-being: A meta-analysis. Int. J. Aging Hum. Dev. 19, 111-132, 1984.

8. House J. S., Umberson D. and Landis K. R. Structures and processes of social support. A. Rev. Sociol. 14, 293-318, 1988.

9. Sarason I. G., Sarason B. R. and Pierce G. R. Social support: The search for theory. J. soc. clin. Psychol. 9, 133-147, 1990

10. Revenson T. A., Schiaffino K. M., Majerovitz S. D. and Gibofsky A. Social support as a double-edge sword: The relation of positive and problematic support to depression among rheumatoid arthritis patients. Soc. Sci. Med. 33, 807.813, 1991

11. Altman D. AIDS in the Mind of America. Anchor Press, Garden City, NY, 1986.

12. Morin S. and Batchelor W. F. Responding to the psychological crisis of AIDS. Publ. Hlth Rep. 99, 4-9, 1984.

13. Fisher J. D. Possible effects of reference group-based social influence on AIDS-risk behavior and AIDS prevention. Am. Psvchol. 43, 914-920, 1988.

14. Smith R. E., Smoll F. L. and Ptacek J. T. Conjunctive moderator variables in vulnerability and resiliency research: Life stress, social support and coping skills, and adolescent sport injuries. J. Person. sac. Psychol. 58, 360-370, 1990

15. Newcomb M. D. Social support and personal characteristics: A developmental and interactional perspective. J. soc. clin. Psychol. 9, 54 68, 1990.

16. Lefcourt H. M., Martin R. A. and Saleh W. E. Locus of control and social support: Interactive moderators of stress. J. Person. soc. Psychol. 47, 378-389, 1984.

17. Williams D. R. Socioeconomic differentials in health: A review and redirection. Soc. Psychol. Q. 53, 81-99, 1990.

18. Berkman L. F. and Syme S. L. Social networks, host resistance, and mortality: A nine-year followup study of Alameda County residents. Am. J. Epidemiol. 109, 186-204, 1979.

19. House J. S., Robbins C. and Metzner H. L. The association of social relationships and activities with mortality: Prospective evidence from the Tecumseh Community Health Study. Am. J. Epidemiol. 116, $123-140,1982$.

20. Kaslow R. A., Ostrow D. G., Detels R., Phair J. P., Polk F. and Rinaldo C. R. Jr, for the Multicenter AIDS Cohort Study. The Multicenter AIDS Cohort Study: Rationale, organization, and selected characteristics of the participants. Am. J. Epidemiol. 126, 310-318, 1987.

21. Kaplan H. B. Methodological problems in the study of psychosocial influences on the AIDS process. Soc. Sci. Med. 29, 277-292, 1989.

22. Rosenberg M. Society and the Adolescent Self-image. Princeton University Press, Princeton, NJ, 1965.

23. Pearlin L. I., Lieberman M. A., Menaghan E. G. and Mullan J. T. The stress process. J. Hlth soc. Behav. 22, 337-356, 1981 .

24. McLaws M., Oldenburg B., Ross M. W. and Cooper D. A. Sexual behaviour in AIDS-related research: Re- liability and validity of recall and diary measures. $J$. Sex Res. 27, 265-281, 1990.

25. Catania J. A., Chitwood D. D., Gibson D. R. and Coates T. J. Methodological problems in AIDS behavioral research: Influences on measurement error and participation bias in studies of sexual behavior. Psychol. Bull. 108, 339-362, 1990.

26. Mayer K. and Pizer H. The AIDS Fact Book. Bantam Books, New York, 1983.

27. Derogatis L. R. SCL-90-R Administration, Scoring and Procedures Manual, Vol. 1. Clinical Psychometric Research, Baltimore, MD, 1977.

28. Veroff J., Douvan E. M. and Kulka R. A. The Inner American. Basic Books, New York, 1981.

29. Andrews F. M. and Withey S. B. Social Indicators of Well-being: Americans Perceptions of Life Quality. Plenum Press, New York, 1976.

30. Coates T. J. Psychosocial research is essential for preventing and treating AIDS. Federation of behavioral, psychological and cognitive sciences, Washington, DC, 1988.

31. Siegel $\mathbf{K}$. and Glassman $\mathbf{M}$. Individual and aggregate level change in sexual behavior among gay men at risk for AIDS. Arch. Sex. Behav. 18, 335-348, 1989.

32. Knight R. G., Waal-Manning H. J. and Godfrey H. P. The relationship between state anxiety and depressed mood: A validity study. J. Behav. Assess. 5, 191-201, 1983.

33. Veit C. T. and Ware J. E. The structure of psychological distress and well-being in general populations. J. Consult. clin. Psychol. 51, 730-742, 1983.

34. Diener E. and Emmons R. A. The independence of positive and negative affect. J. Person. soc. Psychol. 47, 1105-1117, 1985.

35. Cook R. D. Influential obscrvations in linear regression. J. Am. Statist. Ass. pp. 169-174, 1979.

36. Hazan C. and Shaver P. Romantic love conceptualized as an attachment process. J. Person. soc. Psychol. 52, 511-524, 1987

37. Cohen S. Psychosocial models of the role of social support in the etiology of physical disease. Hith Psychol. 7, 269-297, 1988.

38. Fisher J. D. and Misovich S. J. Social influence and AIDS-preventive behavior. In Applied Social Psychology Annual, Vol. 9 (Edited by Edwards J., Tindale R. S., Health L. and Posavac E. J.). Plenum Publishing, New York, 1990.

39. Becker M. H. Factors affecting diffusion of innovations among health professionals. Am. J. publ. Hlth. 60, 294-304, 1970.

40. Martin J. L. Psychological consequences of AIDS-related bereavement among gay men. J. Consult. clin. Psychol. 56, 856-862, 1988

41. O'Brien C. J. K. Primary relationships and mental health in a cohort at risk for AIDS. Dissertation, The University of Michigan (University Microfilms International No. DA8729290), 1987.

42. Pennebaker J. W. and Harber K. Psychosocial responses to the Loma Prieta earthquake. Southern Methodist University and Stanford University. In preparation.

43. Hobfoll S. E. and London P. The relationship of self-concept and social support to emotional distress among women during war. J. soc. clin. Psychol. 4, 189-201, 1986

44. Lieberman M. A. Understanding how groups work. Int. J. Group Psychother. 40, 31-52, 1990.

45. Ingersoll-Dayton $B$. and Morgan D. L. Comparing the influence of positive and negative features of the social environment. Portland State University and The University of Michigan. In preparation. 